\title{
Triangular Framework for Curriculum Development in the Education Sector
}

\author{
Rathnayake Mudiyanselage Dhanapala \\ Department of English Language Teaching, Rajarata University of Sri Lanka, Anuradhapura, Sri Lanka \\ Email:rmdhanapala@yahoo.co.uk
}

How to cite this paper: Dhanapala, R.M. (2021) Triangular Framework for Curriculum Development in the Education Sector. Open Access Library Journal, 8: e7490. https://doi.org/10.4236/oalib.1107490

Received: May 5, 2021

Accepted: June 4, 2021

Published: June 7, 2021

Copyright ( 2021 by author(s) and Open Access Library Inc.

This work is licensed under the Creative Commons Attribution International License (CC BY 4.0).

http://creativecommons.org/licenses/by/4.0/

(c) (i) Open Access

\begin{abstract}
Curriculum planning and subsequent process of course design and implementation are so important in educational programmes that we simply cannot ignore them. Curriculum is essentially a series of activities and learning outcome goals pertaining to each subject. The main purposes of curriculum development are to improve student learning experiences and enhance outcomes by facilitating quality teaching, identifying a suitable syllabus, and assessing learning outcomes. However, educational programmes fail to yield the results of the programmes due to insufficient attention paid to curriculum. Perhaps, the most salient reason for this is the synonymous identification of the terms, curriculum and syllabus. While curriculum is a comprehensive area of study which needs identification of significant disciplines, syllabus could be a factor within the curriculum framework. Literature has proved that possible frameworks or models of curriculum could bring about enormous results. The paper presents a viable curriculum framework mostly suitable for university and the higher education sector with significant areas such as planning, and interrelationships of teaching, learning, assessment, and syllabus. The paper has highlighted the important areas pertaining to curriculum in its framework as a model for curriculum which is useful for development, implementation, revision, and evaluation.
\end{abstract}

\section{Subject Areas}

Education

\section{Keywords}

Planning, Syllabus, Curriculum Framework, Teaching, Assessment

\section{Introduction}

The propensity of curriculum in educational programmes has been an inextrica- 
ble domain of the educational sector. A broader definition of the term curriculum may entail: determining what knowledge, skills, and values students learn; what type of experiences be provided to target intended learning outcomes; planning of teaching and learning experiences; measurement and evaluation of such experiences (Richards, 2001, p. 2) [1]. In order to achieve these, ideal and critical thinking of epistemological issues in the education domain with special reference to individual and societal expectations are to be recognized to help learners to process appropriate learning experiences. In order to materialize the programmes in education, it is advisable to design and implement a suitable curriculum through which programme expectations are achieved. In this context, curriculum models serve immensely based on the study programme and the subject area.

A broader understanding of curriculum would pave way for the identification of appropriate curriculum model or framework. According to Finney (2002, p. 70) [2], curriculum is a term that opens to a variety of definitions based on the narrowest sense and in the wider sense. In the narrowest sense, curriculum is synonymous with the term "syllabus" which specifies the content and order of what is to be taught. In the wider sense, curriculum refers to planning, implementation and evaluation of educational programmes. Richards et al. (1992, p. 94) [3] propose that curriculum is an educational programme which states:

1) The educational purposes of the programme (the ends);

2) The content, teaching procedures and learning experiences that will be necessary to achieve this purpose (the means);

3) Some means for assessing whether or not the educational ends have been achieved.

Similarly, curriculum can be defined as the overall rationale for educational programmes of institutions which include the intentions of the planners, the procedures adopted for the same, the actual experiences of the pupils resulting from the teachers' direct attempts to meet the intentions of planners and the hidden learning that occurs as a by-product of the organization of the curriculum (Kelly, 1989, p. 14) [4].

The definitions given by educationalists in varied disciplines including language teaching very often favour to include the definitions in the broadest sense. Curriculum in the educational context can refer to the whole body of knowledge that children acquire. Richards (2001, p. 39) [1] asserts that curriculum is a broad field of inquiry that deals with what happens in schools and other educational institutions, the planning of instructions, and the study of how curriculum plans are implemented. Adding more concern to the topic of curriculum, Tyler (1949, p. 1) [5] posited four fundamental questions that must be answered in developing any curriculum and thus include:

1) What educational purposes should the school seek to attain?

2) What educational experiences can be provided that is likely to attain these purposes?

3) How can these educational experiences be effectively organized? 
4) How can we determine whether these purposes are being attained? (Tyler, 1949)

Some of the definitions given by educators on curriculum have been confined to learning or the teaching process. Lewis and Miel (1972) [6] paid emphasis on the following categories in their definition of curriculum.

- Course of study.

- Intended learning outcomes.

- Intended opportunities for engagement and learning opportunities provided.

- Learner's actual engagements and experiences.

The definition of Lewis and Miel (1972) [6] paid special emphasis on the identification of a set of intentions of opportunities for engagement in the case of learner and the role emphasized on the teacher. Tanner and Tanner (1975) [7] too paid emphasis on limited aspects in the definitions of the curriculum. Thus, their definition included:

- The cumulative traditions of organized knowledge.

- Modes of thought.

- Race experience.

- A planned learning environment.

- Cognitive/affective content and process.

- An instructional plan.

- Instructional ends or outcomes.

The influence of scientific management approach particularly used in business and industry had much impact on curriculum paying attention to the identification of objectives of curriculum based on skills and knowledge needed by learners. In the early twentieth century, Bobbitt (1918) [8] introduced a pragmatic definition to the term curriculum and later Tyler (1949) [5] too contributed a model that systematized the objectives-based approach. Bobbitt (1918) [8] defined curriculum as "that series of things which children and youth must do and experience by way of developing abilities to do things well that make up affairs of adult life; and to be in all respects what adults should be." Tyler (1957) [9] offered a broader definition and thus identified curriculum as "all of the learning of students which is planned by and directed by the school to obtain to attain its educational goals."

Some curriculum writers have conceived curriculum as an instructional plan. Macdonald (1965) [10] views curriculum as "those planning endeavors which take place prior to instruction.” Beauchamp (1972) [11] is of the view that curriculum is a document that is designed to be used as a point of departure for instructional planning. Saylor et al. (1981) [12] offering a similar definition, define curriculum as "a plan for providing sets of learning opportunities for persons to be educated."

It is commonly admitted that mere planning of an educational programme would not make any effect until learners become engaged with opportunities. Though these definitions deal with an important aspect of curriculum, in prag- 
matic sense, they lack emphasis on areas such as process of instructions and how these instructions are carried out, tested for, appropriateness and the related activities that support the main aim that is learning.

Most of the above definitions conveyed only a partial explanation of the term curriculum and many of the aspects relating to curriculum such as pragmatic aspects, learner's willful growth in personal social competence, formal and informal activities included and the assessment and its implication for measurement and evaluation are not paid special attention to. Further, these definitions pose us to the process pertinent to the question of how do children acquire knowledge, who are involved in the process, what are the essential requirements in the process and when and how to plan this process; before, during, and after in the context of curriculum development.

\section{Distinction of Syllabus and Curriculum}

In spite of the salient practice of associating syllabus with curriculum, educators have argued that syllabus is a sub-category of curriculum and an arrangement of the content which identifies what to teach and test in a course (Breen, 2001 [13]; McKay, 1980 [14]; Richards, 2001 [1]). Further, according to Breen (2001) [13], curriculum represents a broader perspective where different elements of a teaching procedure such as aims, content, methodology and evaluation are addressed.

Course designing process has to undergo a rigorous framework of curriculum planning. The term syllabus is a major contributor to the curriculum of educational programmers. It is apparent that there are confusions over the terms; curriculum and syllabus. In his investigation of the two terms curriculum and syllabus, White (1988) [15] explores that a distinction that is commonly drawn in Britain, "syllabus" refers to the content or subject matter of an individual subject, while "curriculum" means the totality of the content to be taught. Further, it is through the curriculum that the aims of educational programmes are realized. In contrast, according to White, curriculum and syllabus are terms that tend to be synonymous in the USA.

Nunan (1987), (cited in Graves, 1996, p. 3 [16]) views curriculum as the philosophy, purpose, design and implementation of a whole programme. In order to fulfill the areas such as design and implementation of a whole programme described by Nunan, to elaborate the term curriculum, it should be understood that syllabus becomes an important tool. Hence, it would be desirable to admit the notion that syllabus is a major tool in the broader framework of curriculum and it is worth considering syllabus as a sub section of the curriculum. White (1998) [15] views a syllabus narrowly as the specification and ordering of content of a course or courses. Thus, syllabus design is a part of course development. The role of the curriculum in the design and development of course is to function as an overall framework of activities both learning and teaching that could appear on a prospective plan.

Dubin and Olshtain (1986, p. 35) [17] prefer to define curriculum and syllabus 
as separate entities, in order to call attention to their particular functions, even though one document could contain sections which express separate purposes. Further, they elaborate that a curriculum contains a broad description of general goals by indicating an overall educational cultural philosophy and reflect national and political trends as well and in the case of a syllabus it is a more detailed and operational statement of teaching and learning elements which translates the philosophy of the curriculum into a series of planned steps mostly leading towards narrowly defined objectives. Hutchinson and Waters (1987, p. 80) [18] are of the view that a syllabus is a document that directs us to what should be learnt. They claim that, the question "what should be learnt" need to pass through several stages.

It is apparent from the literature available that curriculum and syllabus are considered as two related but separate domains in the field of education. However, syllabus cannot function on its own without the curriculum framework which is considered to be broader.

\section{Models of Curriculum Planning}

A model is a representation of a process or activity with elements involved leading to a conceptual framework. Since the $18^{\text {th }}$ century, the concept of curriculum has been a subject of discussion in the field of education. The models on curriculum planning and development proposed by theorists and authors are diverse. As education is a dynamic and evolving process, curriculum development tends to shape up accordingly by being dynamic.

Various curriculum models have been proposed by many experts in education and some of them can be identified as: Ralph Tyler Model-1949, Wheeler's Cyclic Model-1971, and Walker's Model-1972. These models have been discussed in brief below.

The Tyler Model developed by Ralf Tyler in the 1940s is on par with curriculum development in the scientific approach. This model is one of the first models which are highly simple and it consists of four steps. Step one is determining the objectives of the school or class which specify what students need to do in order to be successful. Step two is the development of learning experiences of students possibly through teaching. Step three is the organizing the experiences of students. This could be done through teaching according to teacher's philosophy and the needs of students. The final step is the evaluation of the objectives. Through evaluation, teacher can assess whether students have achieved the objectives of the lesson.

The Wheeler Model of curriculum development is known as cyclic model which specifies that curriculum should be a continuous cycle responsive to changes in education process. Further, the model makes appropriate adjustments to these changes. This model consists of five interconnected stages:

1) Aims, goals and objectives;

2) Selection of learning experiences; 
3) Selection of content;

4) Organization and integration of learning experiences and content;

5) Evaluation.

However, a detailed situational analysis indicates that this model is a timeconsuming process.

The final model introduced in this section is the Walker's Model which has three phases. The first one is the "platform" which includes "ideas, preferences, points of view, beliefs and values about the curriculum. The second is the deliberations in which interaction between stakeholders begins and clarification of views and ideas in order to reach a consensus of a shared vision. The final is the stage in which curriculum developers actually make decisions, which are based on deliberations (above). These decisions affect curriculum documents and materials production.

Further, in literature, models of curriculum are also based on conceptualizations namely; curriculum as process, curriculum as product, and curriculum as praxis (Esseys, UK, 2018) [19]. The process-models of curriculum thinkers are more concerned with the pathway which learners take through a course. Contrary to that, the product-oriented models of curriculum focus on destinations rather than the process. The product-centred models are also known as objectives model of which Ralph Tyler was mostly associated with. Praxis, in the sense of critically-informed practice, has long been an aspect of academic and philosophical inquiry into education. Praxis-focused conceptualizations of curriculum focus on the concept that curricula are designed and taught not merely out of unquestioning obedience, or through managerial order/rule, but because there are aspects of teaching which accord with the individual's philosophical or political attitudes to the world.

\section{Triangular Framework for Curriculum Development}

The intension of the paper is to propose a comprehensive curriculum framework to be considered in the education sector. The proposed curriculum framework is more feasible for all aspects of education in general and second language teaching in particular and serves as a model for curriculum development and revision of programmes particularly in the university and higher education sector. The name assigned for the proposed framework is "Triangular Framework for Curriculum Development".

As shown in the Figure 1, the framework (Dhanapala, 2012) [20] contains three important domains of curriculum; Teaching, Learning and Assessment and having the syllabus component as the core for all the three disciplines. For the smooth function of study programmes, these three areas with syllabus in the middle are important in order to maintain the diversity and comprehensibility. The outer circle of the figure represents the process of planning. The development of any educational activity or curriculum needs to undergo a stage of planning. Planning would involve: Convening a Curriculum Development Committee, Identifying 


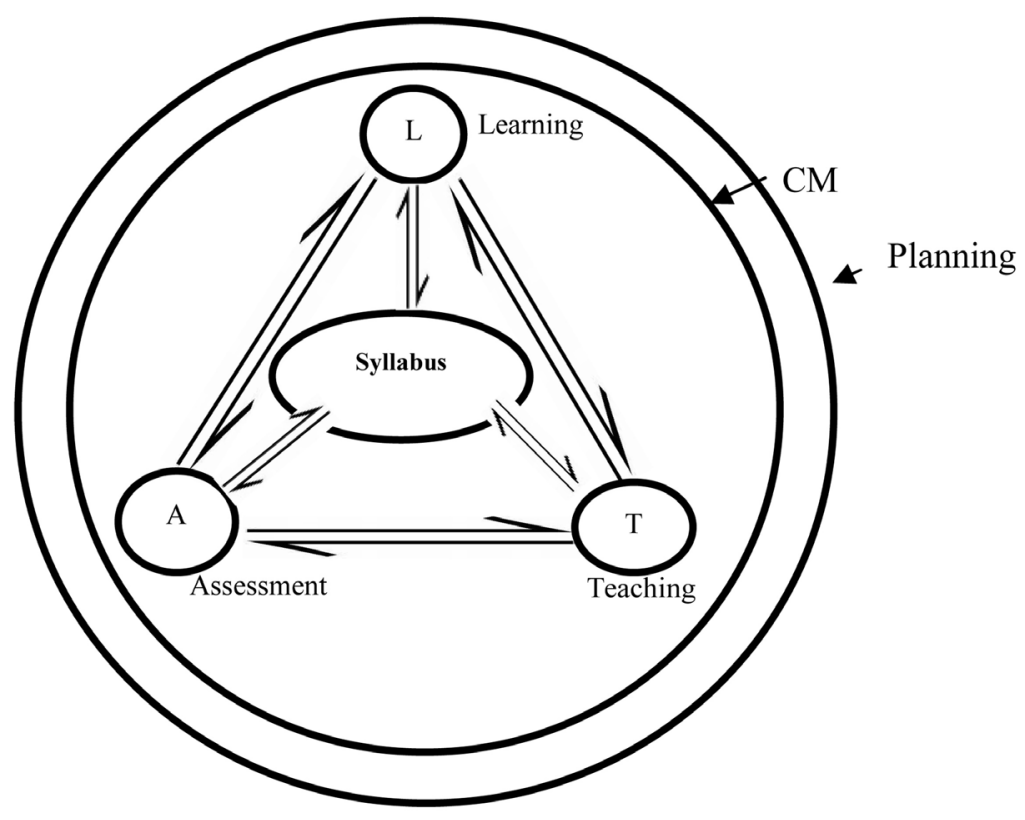

Figure 1. Adapted version of triangular framework for curriculum development (Dhanapala, 2012).

Key Issues and Trends in the Specific Content Areas, and Needs Analysis. Curriculum planning is considered to be a complex process where the faculty of authority define intended learning outcomes, assessments, content, national and global requirements, and pedagogic requirements necessary for students' success across an entire curriculum. The Teaching and Learning departments, educational consultants provide planning in curriculum to faculties and departments to facilitate high-quality learning experiences for students. In the case of language teaching, the same layer can be regarded as language planning (LP). The planning stage of curriculum development involves five phases which include goals determination, technical operation, the application stage, implementation stage, and evaluation stage (Longe, 1984) [21].

The second circle in the diagram represents the body of curriculum in which triangular elements and the syllabus are embodied. The three vital elements included in the curriculum framework are learning, assessment, and teaching and in the core is the syllabus all of which are interconnected. The interrelationship of the framework and the backwash effect of the components are indicated with the arrows shown.

In curriculum designing or development, teaching component needs special consideration. The teaching constituent represents; teacher, methodology, materials and the technology used. Further, curriculum developers need to account the teaching component with special reference to teaching mode which includes online, physical, blended, and even postal. Perhaps, a combination of modes can be considered in the design.

The framework elaborated by Bloom and his collaborators in the teaching context can be considered which consisted of six major categories: Knowledge, 
Comprehension, Application, Analysis, Synthesis, and Evaluation. The categories after Knowledge were presented as "skills and abilities," with the understanding that knowledge was the necessary precondition for putting these skills and abilities into practice. While each category contained subcategories, they lie along a continuum starting from simple to complex and concrete to abstract, the taxonomy is popularly remembered according to the six main categories (Armstrong, 2010) [22]. When teaching is concerned, it is connected to learning, assessment and syllabus. In a curriculum, any of these areas cannot be simply ignored. In the case of teaching, what should be taught is based on the syllabus and the feedback from teaching helps to identify the content of the syllabus. Similarly, the feedback derived from assessment and learning towards teaching helps to improve teaching. The backwash effect of learning (how effectively students learn) and assessment (how effectively students perform) help to improve the area of teaching.

The next component learning embodies; learner, motivation, learner attainment and learner perspectives. Moreover, it is mandatory that developers of curriculum have to consider myriad of modes for learning which include self-learning, classroom based (physical) learning, and provision of self-access through laboratories etc. The attainment levels of learning are measured through the assignment and the assignment component provide necessary feedback for learning. Also, how effective learning is conditioned by the component of teaching. The notion that effectiveness of teaching embodies learning is considered here. For learning, syllabus always provides the necessary content and the environment which focuses, knowledge, skills, and attitudes (KSA).

Assessment, which is yet another compulsory component, includes testing and evaluation which can be summative, formative, informal, and continuous. When assessment is concerned, what should be assessed is determined by the syllabus and the results obtained at tests (assessment) help to improve the syllabus in one instance. Assessment is associated with teaching and learning and assessment yields an observed judgement of the effectiveness of teaching (Richards \& Renandya, 2002) [23]. The quality and the difficulty level of assessment are conditioned by learning and how teaching is performed. Further, assessments provide feedback for both learning and teaching in turn. Assessment is an important element of curriculum and it is deemed necessary that curriculum developers should consider the modes of assessment that should be taken into account when planning curriculum depending on the subject area.

Finally, the syllabus which is in the core of the proposed framework is a pivotal area in curriculum design. The syllabus contains the mass of knowledge to be learnt in manageable units and the role of syllabus varies from different points of the teaching material which inspires the production of texts and exercise and the basis on which proficiency will be evaluated. Syllabus is the determiner of entire course (Hutchinson and Water, cited in Lolita, 2007, p. 14) [24]. The subject matter, knowledge and skills of the study area should be embedded in the syllabus with the help of study materials such as text books, work books, handouts, 
and perhaps in the digital modes. All these areas are mutually connected to learning, assessment, and teaching as per the framework (Figure 1).

\section{Conclusions}

It has been observed that curricula of educational programmes simply contain only the contents of the syllabus. However, literature has proved that curriculum is a comprehensive educational concept in which philosophical, social and administrative factors are involved with planning and implementation. The important areas in a curriculum are deemed to have been neglected by some educationalists. The paper presented a viable curriculum framework mostly suitable for university and the higher education sector with significant areas such as planning, and interrelationships of teaching, learning, assessment, and syllabus. The paper has highlighted the important areas pertaining to curriculum in its framework as a model for curriculum development, implementation, revision, and evaluation.

One of the limitations of the paper is that the triangular framework model serves as a basic structure of curriculum development and it contains abstract elements which have to be turned into active agents in the process of curriculum development. Another limitation of the paper is that the model presented does not specify detailed descriptions of curriculum and syllabus frameworks. Yet, the model presented in the paper opens avenues for educational planners and curriculum developers to map out how curriculum should be planned, developed, implemented, and evaluated. It is expected that the contents of the paper and the triangular framework presented could open avenues for prospective researchers to engage in detailed studies on curriculum.

The main contribution of the paper is to introduce an adapted curriculum framework of the same author and enlighten professionals and planners in the education sector with essential components that need to be taken into account in the process of manipulation of such elements so as to yield better results when planning programmes in education.

\section{Conflicts of Interest}

The author declares no conflicts of interest regarding the publication of this paper.

\section{References}

[1] Richards, J.C. (2001) Curriculum Development in Language Teaching. CUP, Cambridge. https://doi.org/10.1017/CBO9780511667220

[2] Finney, D. (2002) The ELT Curriculum. In: Richards, J.C. and Renandya, W.A., Eds., Methodology in Language Teaching, Cambridge University Press, Cambridge, 70 .

[3] Richards, J.C., Platt, J. and Platt, H. (1992) Longman Dictionary of Language Teaching and Applied Linguistics. Longman, Pearson Education Limited, Essex.

[4] Kelly, A.V. (1989) The Curriculum Theory and Practice. Paul Chapman Publishing, 
London.

[5] Tyler, R.W. (1949) Basic Principles of Curriculum and Instruction. University of Chicago Press, Chicago.

[6] Lewis, A.J. and Miel, A. (1972) Supervision for Improved Instruction: New Challenges, New Responses. Wadsworth Publishing Company, Inc., Belmont.

[7] Tanner, D. and Tanner, L.N. (1975) Curriculum Development-Theory into Practice. Macmillan Publishing Co., Inc., New York.

[8] Bobbitt, F. (1918) The Curriculum. Houghton Mifflin Company, Boston.

[9] Tyler, R.W. (1957) The Curriculum Then and Now. In: Proceedings of the 1956 Invitational Conference on Testing Problems, Educational Testing Service, Princeton, 79.

[10] Macdonald, J.B. (1965) Educational Models for Instruction. In: Macdonald, J.B. and Leeper, R.R., Eds., Theories in Instruction, Association for Super Vision and Curriculum Development, Washington DC, 5.

[11] Beauchamp, G.A. (1972) Basic Components of a Curriculum Theory. Curriculum Theory Network, 3, 16-22. https://doi.org/10.2307/1179213

[12] Saylor, J.G., Alexander, W.M. and Lewis, A.J. (1981) Curriculum Planning for Better Teaching and Learning. Holt, Rinehart and Winston, New York.

[13] Breen, M.P. (2001) Syllabus Design. In: Carter, R. and Nunan, D., Eds., The Cambridge Guide to TESOL, Cambridge University Press, Cambridge, 151-159. https://doi.org/10.1017/CBO9780511667206.023

[14] McKay, S. (1980) On Notional Syllabus. Modern Language Journal, 64, 179-186. https://doi.org/10.1111/j.1540-4781.1980.tb05182.x

[15] White, R.V. (1988) The ELT Curriculum: Design Innovation and Management. Blackwell, Oxford.

[16] Graves, K. (1996) Teachers as Course Developers. Cambridge University Press, Cambridge. https://doi.org/10.1017/CBO9780511551178

[17] Dubin, F. and Olshtain, E. (1986) Course Design. Developing Programs and Materials for Language Learning. Cambridge University Press, Cambridge.

[18] Hutchinson, T. and Waters, A. (1987) English for Specific Purposes: A Learning Centered Approach. Cambridge University Press, Cambridge.

https://doi.org/10.1017/CBO9780511733031

[19] Essays, UK (2018) Models of Curricula/Curriculum Design Lecture. https://www.ukessays.com/lectures/education/planning/curriculum/?vref=1

[20] Dhanapala, R.M. (2012) Impact of ELT Programmes of the Faculty of Management Studies of Rajarata University of Sri Lanka on the English Language Proficiency Needs of the Private Sector Business Organizations: A Case Study. Unpublished M. Phil. Dissertation, University of Kelaniya, Kelaniya.

[21] Longe, R.S. (1984) Planning for a Responsive Curriculum. In: Obanya, P., Ed., Curriculum, in Theory and in Practice, Educational Research and Study Group, Ibadan.

[22] Armstrong, P. (2010) Bloom's Taxonomy. Vanderbilt University Center for Teaching, Nashville. https://cft.vanderbilt.edu/guides-sub-pages/blooms-taxonomy

[23] Richards, J.C. and Renandya, W.A. (2002) Methodology in Language Teaching: An Anthology of Current Practice. Cambridge University Press, Cambridge.

https://doi.org/10.1017/CBO9780511667190

[24] Lolita, Y. (2007) The Computer-Based Teaching in Elementary Schools. State University of Surabaya: Comprehensive Paper. 